\title{
REPORT ON PROFICIENCY TESTING
}

\section{Annual Report on the External Quality Assessment Scheme for Clinical Parasitology in Korea (2017)}

Eun Jeong Won ${ }^{1}$, Ji Seung Jung ${ }^{1}$, Myung Geun Shin ${ }^{2}$, Jong Hee Shin', and Soon Pal Suh $^{2}$

Departments of ${ }^{1}$ Parasitology and Tropical Medicine and ${ }^{2}$ Laboratory Medicine, Chonnam National University Medical School, Gwangju, Korea

Corresponding author: Eun Jeong Won

Department of Parasitology and Tropical Medicine, Chonnam National University Medical School, 160 Baekseo-ro, Donggu, Gwangju 61469, Korea Tel: +82-61-379-2701 Fax: +82-61-375-5834

E-mail: Parasite.woni@jnu.ac.kr

pISSN: $2384-2458$

elSSN: 2288-7261
Annual proficiency surveys were conducted in March, May, and August of 2017 as the Korean Association of External Quality Assessment Service. Overall, four image samples (MPI-17-01, MPI-17-02, MPI-17-03, MPI-17-04) in the first trial, three image samples (MPI-17-05, MPI-17-06, MPI-17-07) in the second trial, and a slide specimen (MPS-17-01) using parasite samples in the third trial were distributed to participating institutions. The first and second trial specimens were prepared by photographing slides made of formalinether concentrate of positive samples stored for educational purposes. The slide distributed in the third trial was prepared using cellophane tape, which was stored after diagnosis of the patients infected with Enterobius vermicularis. There were 191 participating institutions in the first, 204 in the second, and 212 in the third trial. The correct identification rates were 27.2\% for MPI-17-01 Diphyllobothrium species (sp.), 96.6\% for MPI-17-02 no parasite, 67.5\% for MPI-17-03 Metagonimus yokogawai, 71.2\% for MPI-17-04 Balantidium coli, 99.0\% for MPI-17-05 Taenia sp., 99.0\% for MPI-17-06 Trichuris trichiura, 92.7\% for MPI17-07 Cryptosporidium sp., and 96.7\% for MPS-17-01 E. vermicularis. The current external quality assessment for clinical parasitology was performed using image samples and standard slides. Surveys of parasitic infections should be accompanied by continuous education on various parasitic infections, for which there was lack of experience of inspection in clinical laboratories. In the future, it will be necessary to establish a standard material using parasitic samples, and ultimately to conduct a survey on whole series of tests for the diagnosis of parasitic diseases.

(J Lab Med Qual Assur 2018;40:21-26)

Key Words: Quality control, Parasitology

\section{서론}

대한임상검사정도관리협회에서는 자발적인 참여신청기관 을 대상으로 임상기생충 분야에서 신빙도조사를 제공하고 있 다. 대한임상검사정도관리협회 임상미생물학분과를 중심으로 국내 임상미생물검사실의 수준이 발전하는 데 따라 모든 항목 들에 대해 종합적인 신빙도조사 프로그램을 제공하는 것을 목 표로 지난 10 년간 모듈을 확대해왔지만, 국제적인 신빙도조사 사업에 비교하여 다소 미흡한 점이 있을 수밖에 없었다[1-4]. 특히 임상기생충 분야는 우수검사실 신임인증평가 항목 중 임 상미생물에 속해 있지만, 대부분 배양이 되지 않고, 이에 따른 표준물질의 확보가 매우 어렵다는 점, 약제 감수성 검사의 필 요성이 낮다는 점이 다른 임상미생물 항목과는 크게 다르다.
현재 국내 임상검사실에서 시행하는 기생충검사는 주로 장내 기생충에 집중하여 현미경을 이용한 대변검경법을 이용하고 있다[5]. 국내 장내기생충의 유병률이 감소함에 따라 그 민감 도는 감소한 반면, 현미경적 진단법은 관찰자에 따라 주관적이 며, 검경 경력에 따른 차이가 발생할 수 있다는 한계를 갖고 있 다. 지금까지는 국내에서 활용 가능한 기생충 관련 표준물질의 보급이 어려워 대변검경법에 대한 내부정도관리는 미진한 실 정이며, 신빙도조사를 통한 외부정도관리 역시 이미지에 의존 할 수밖에 없는 실정이었다[5,6]. 이번 2017년 신빙도조사의 기생충검사 프로그램에서는 기존 이미지뿐만 아니라 기생충 시료를 이용한 슬라이드를 제작하여 배포하고 이에 대한 검경 능력을 비교 · 분석하고자 하였다. 또한 2017년 신빙도조사의 기생충검사 프로그램 결과를 종합적으로 분석하고, 질 관리수 
준, 문제점 분석, 향상방안 등을 제시하고자 하였다.

\section{재료 및 방법}

\section{1. 신빙도조사 방법}

2017년 신빙도조사사업은 3, 5, 8월에 걸쳐 3회 시행하였으 며, 1 차는 4 개의 이미지 검체(MPI-17-01, MPI-17-02, MPI$17-03, \mathrm{MPI}-17-04), 2$ 차는 3 개의 이미지 검체(MPI-17-05, MPI-17-06, MPI-17-07), 마지막 3차는 기생충 시료를 이용 한 슬라이드 검체(MPS-17-01)를 참여기관에 배부하였다. 1 차에는 하단에 가로 사이즈 마커를 포함시킨 이미지 파일을 각 문항당 1 개씩 제작하여 배포하였다. 2 차에는 하단에 가로 및 세로 사이즈 마커를 포함시킨 이미지 1 개와 함께 가상 환자 의 임상적 배경을 제시하고 이를 portable document format $(\mathrm{PDF})$ 파일로 배포하였다. 3 차에는 기생충 충란이 포함된 슬 라이드를 250 여 개 제작하여 각 기관에 배포하였다. 모든 신청 과 결과입력, 결과판정 등은 대한임상검사정도관리협회 홈페 이지에 구축된 신빙도조사 프로그램(http://eqas.keqas.org/) 을 이용하였다.

\section{2. 관리물질}

1 차에는 기생충 양성소견 3 개 및 음성소견 1 개를, 2 차에 는 기생충 양성소견 3 개를, 3 차에는 기생충 양성소견 1 개 를 포함시키고자 하였다. 기생충은 선충류, 흡충류, 조충류 및 원충류를 다양하게 포함시켜 분배하였는데, 1차에는 흡충 류 1종(ova of Metagonimus yokogawai), 조충류 1종(ova of Diphyllobothrium nihonkaiense), 원충류 1종(cyst of Balantidium coli)을, 2차에는 선충류 1종(ova of Trichuris trichiura), 조충류 1종(ova of Taenia saginata), 원충류 1종 (cyst of Cryptosporidium parvum)을, 3차에는 선충류 1종 (ova of Enterobius vermicularis)을 선별하였다. 이미지 검체 는 교육용으로 보관 중인 양성 시료의 포르말린-에테르 농축 액을 이용하여 제작한 슬라이드를 촬영하여 제작하였다. 3차 신빙도조사에 배포한 슬라이드는 셀로판테이프법에서 요충 충란을 확인하여 요충증을 진단한 후 보관 중이던 셀로판테이 프를 이용하여 제작하였다. 제작한 슬라이드는 기생충 충란 검 경에 숙련된 2 인이 검경하여 요충 충란을 확인한 경우만 선별 하여 표준 슬라이드로 배포하였다.

\section{3. 결과 판정 및 해석}

기생충 동정은 종수준까지 맞는 경우 또는 임상적으로 속 수준의 동정이 의미가 있다면 속수준까지 맞는 경우를 '적절 (acceptable)'하다고 판정하였다. 이 기준에 맞지 않은 답을 하거나 답하지 않은 경우 ‘부적절(unacceptable)'로 판정하였 다. 1 차 신빙도조사의 경우 이미지 사이즈의 오류로 인한 일부 기관에서의 오판독 가능성이 제기되어 전체 기관의 결과값의 일치도가 $80 \%$ 에 미달이면 판정을 보류하였다.

\section{결과}

2017년 기생충검사 신빙도조사결과는 Table 1에 정리하였 다. 참여기관은 1 차에서 191 기관, 2 차에서 204 기관, 3 차에서 212기관이었다. 1차의 경우 MPI-17-01 Diphyllobothrium species (sp.)는 $27.2 \%$, 기생충이 없었던 MPI-17-02는 $96.6 \%$, MPI-17-03 Metagonimus yokogawai는 67.5\%, MPI-1704 Balantidium coli는 71.2\%의 정답률을 보였다. 2차의 경 우 MPI-17-05 Taenia sp.는 99.0\%, MPI-17-06 Trichuris trichiura는 99.0\%, MPI-17-07 Cryptosporidium sp.는 $92.7 \%$ 의 정답률을 보였다. 3차의 경우 MPS-17-01 Enterobius vermicularis는 $96.7 \%$ 의 정답률을 보였다. 결과보고 서는 공통보고서와 기관별보고서 두 가지 형태로 제공하였는 데, 공통보고서에는 해당 회차에 포함된 기생충 진단에 특징적 인 소견과 배부한 이미지를 제공하였고, 기관별 보고서에서는 각 기관의 결과값과 판정소견, 그리고 전체기관에서 응답한 결 과값의 종류 및 수와 분율을 제공하였다(Fig. 1).

\section{고찰}

기생충검사 프로그램에서의 신빙도조사사업은 적절한 표준 물질의 확보가 어려운 탓에 확대되기 어려운 한계를 가지고 있 어, 기생충 충란 이미지를 이용한 검경능력에 대한 비교·분석 을 수행해 왔다[4]. 이번 2017년 1차 신빙도조사의 경우 각 기 생충 진단을 위한 ova 또는 cyst 이미지를 1 개씩 제공하였는 데, 전산시스템에서 구현되는 과정에서 이미지의 가로 길이가 임의로 축소되면서 충란 모양이 왜곡되고 사이즈 마커가 짧아 지는 현상이 일부 기관에서 확인되었다. 모든 기관에서 동일한 전산시스템의 오류가 확인되지는 않았으나, 동일한 조건이 가 정되어야 하는 신빙도조사사업의 전제를 감안하여 전체 기관 의 결과값 일치도가 $80 \%$ 에 미달이었던 기생충 양성소견 3 개 에 대해서는 판정을 보류하였다. 이후 가로 및 세로 사이즈 마 커를 추가하고 $\mathrm{PDF}$ 파일로 형식을 바꿔 이미지 검체의 임의적 인 왜곡을 방지하고자 하였으며, 가상 환자의 임상적 배경을 추가로 제시함으로써 기생충 동정에 도움을 주고자 하였다. 이 를 통해 2차 신빙도조사에서는 92.7\%-99.0\%의 높은 정답률 


\section{Journal of LABORATORY MEDICINE and QUALITY ASSURANCE}

Eun Jeong Won et al • EQA for Clinical Parasitology

Table 1. Performance of laboratories in microscopic examination of stools in clinical parasitology

\begin{tabular}{|c|c|c|c|c|c|c|}
\hline Trial no. & Specimen no. & $\begin{array}{c}\text { No. of } \\
\text { participants }\end{array}$ & $\begin{array}{l}\text { Organisms identified with } \\
\text { acceptable accuracy }\end{array}$ & No. (\%) & $\begin{array}{l}\text { Organisms identified with } \\
\text { unacceptable accuracy }\end{array}$ & No. $(\%)$ \\
\hline \multirow[t]{31}{*}{ Trial I } & MPI-17-01* & 191 & Diphyllobothrium sp. & $52(27.2)$ & Subtotal & $139(72.8)$ \\
\hline & & & & & Trichostrongylus & $65(34.0)$ \\
\hline & & & & & Enterovirus vermicularis & $36(18.8)$ \\
\hline & & & & & Ascaris sp. & $17(8.9)$ \\
\hline & & & & & Metagonimus yokogawai & $7(3.7)$ \\
\hline & & & & & Fasciola hepatica/Fasciola buski & $6(3.1)$ \\
\hline & & & & & Hookworm & $4(2.1)$ \\
\hline & & & & & Paragonimus sp. & $2(1.0)$ \\
\hline & & & & & Trichostrongylus orientalis & $1(0.5)$ \\
\hline & & & & & Trichostrongylus sp. & $1(0.5)$ \\
\hline & MPI-17-02 & 191 & No parasite observed & $185(96.9)$ & Subtotal & $6(3.1)$ \\
\hline & & & & & Schistosoma japonicum & $2(1.0)$ \\
\hline & & & & & Enterovius vermicularis & $1(0.5)$ \\
\hline & & & & & Chilomastix mesnili & $1(0.5)$ \\
\hline & & & & & Diphyllobothrium sp. & $1(0.5)$ \\
\hline & & & & & No response & $1(0.5)$ \\
\hline & MPI-17-03* & 191 & Metagonimus yokogawai & $129(67.5)$ & Subtotal & $62(32.5)$ \\
\hline & & & & & Enterovius vermicularis & $44(23.0)$ \\
\hline & & & & & Clonorchis sp. & $12(6.3)$ \\
\hline & & & & & Diphyllobothrium sp. & $1(0.5)$ \\
\hline & & & & & Fasciola hepatica/Fasciola buski & $1(0.5)$ \\
\hline & & & & & Giardia lamblia & $1(0.5)$ \\
\hline & & & & & Hymenolepis nana & $1(0.5)$ \\
\hline & & & & & No parasite observed & $1(0.5)$ \\
\hline & & & & & Trichostrongylus & $1(0.5)$ \\
\hline & MPI-17-04 & 191 & Balantidium coli & $136(71.2)$ & Subtotal & $55(28.8)$ \\
\hline & & & & & No parasite observed & $51(26.7)$ \\
\hline & & & & & Clonorchis sp. & $1(0.5)$ \\
\hline & & & & & Entamoeba histolytica/E. disper & $1(0.5)$ \\
\hline & & & & & Giardia lamblia & $1(0.5)$ \\
\hline & & & & & Taenia sp. & $1(0.5)$ \\
\hline \multirow[t]{13}{*}{ Trial II } & MPI-17-05 & 204 & Taenia sp. & $202(99.0)$ & Subtotal & $2(1.0)$ \\
\hline & & & & & Ecchinococcus sp. & $1(0.5)$ \\
\hline & & & & & Trichuris trichiura & $1(0.5)$ \\
\hline & MPI-17-06 & 204 & Trichuris trichiura & $202(99.0)$ & Subtotal & $2(1.0)$ \\
\hline & & & & & Taenia sp. & $1(0.5)$ \\
\hline & & & & & Trichomonas hominis & $1(0.5)$ \\
\hline & MPI-17-07 & 204 & Cryptosporidium sp. & $189(92.7)$ & Subtotal & $15(7.4)$ \\
\hline & & & & & Entamoeba histolytica/E. disper & $5(2.5)$ \\
\hline & & & & & Cystoisospora (Isospora) belli & $3(1.5)$ \\
\hline & & & & & Endolimax nana & $2(1.0)$ \\
\hline & & & & & Entamoeba coli & $1(0.5)$ \\
\hline & & & & & Entamoeba hartmanni & $1(0.5)$ \\
\hline & & & & & No parasite observed & $3(1.5)$ \\
\hline Trial III & MPS-17-01 & 212 & Enterobius vermicularis & $205(96.7)$ & No parasite observed & $7(3.3)$ \\
\hline
\end{tabular}

Abbreviation: sp., species.

${ }^{\star}$ Excluded from evaluation because of low consensus. 


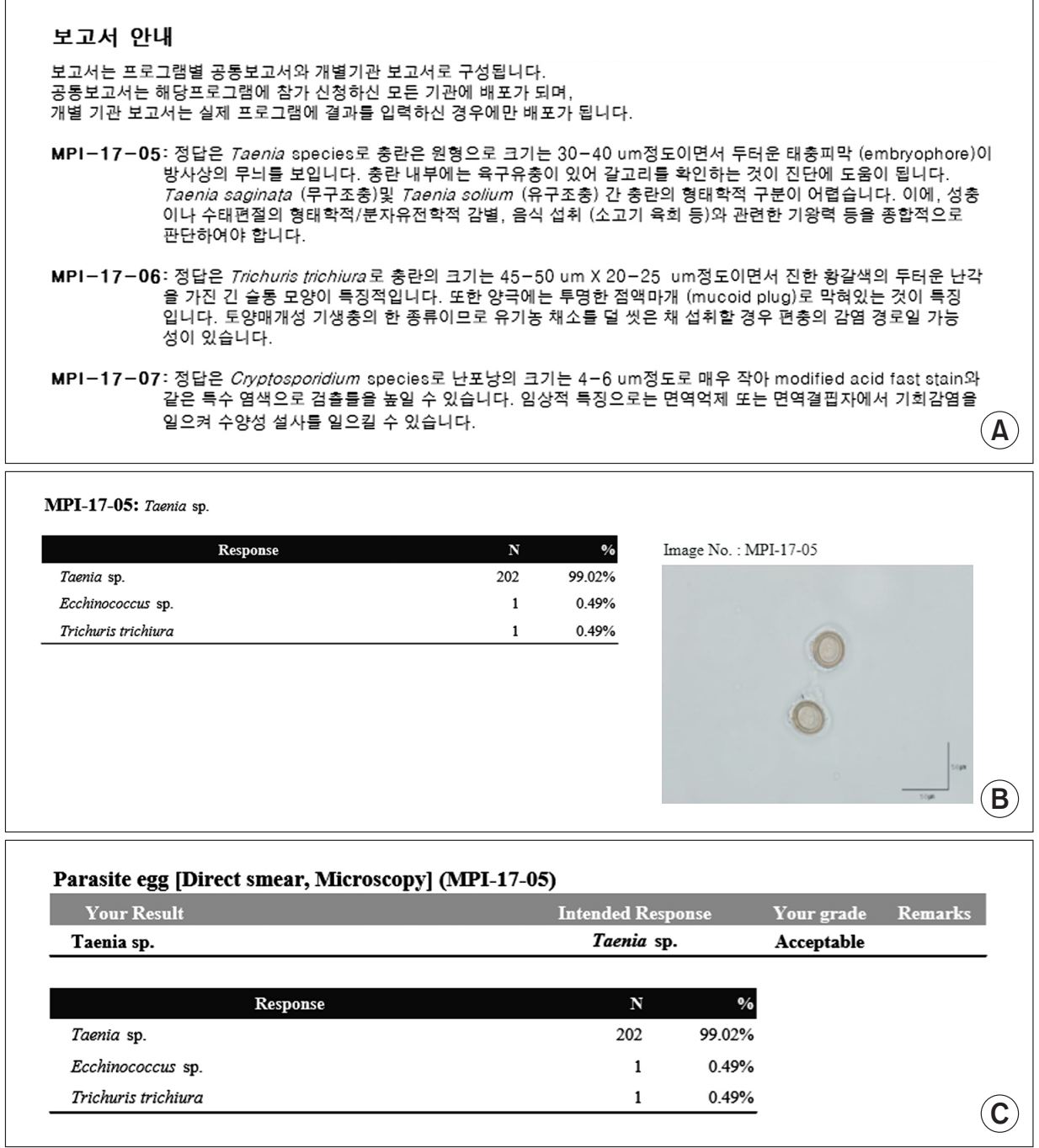

Fig. 1. Summary report of clinical parasitology program. (A, B) Summary of all participants. (C) Summary of each laboratory.
을 보여, 이미지 검체를 이용한 적절한 수준의 신빙도조사가 이뤼질 수 있었다고 판단되었다. 하지만 선충류 및 조충류 충 란에 비해 원충류인 Cryptosporidium sp.는 정답률이 비교적 낮고, 다양한 오답을 보였다. 이는 국내 검사실에서 원충류에 대한 검경 경험이 상대적으로 적기 때문으로 판단되었다. 실 제 국내 임상검사실에서 대변검사의 내부정도관리 현황을 파 악한 연구결과에 따르면, 대다수 기관(74.4\%)들이 원충류 진 단을 위한 특수염색을 시행하고 있지 않고 있다고 답변하였다 [5]. 원충류에 대해서는 현미경적 진단법이 상대적으로 낮은 민감도를 보임은 잘 알려진 사실이며[7], 이를 보완하기 위해 ELISA (enzyme-linked immunosorbent assay)법이나 다양 한 중합효소연쇄반응을 이용하는 진단법이 이용될 수 있지만, 무엇보다도 특수염색이 비용 효과적이다[5]. 무엇보다도 설사 환자에서 원충류 감염이 의심되는 경우에는 원충류 진단을 위 한 특수염색을 시행하는 것이 현재 검사실 실정에 적합하리라
고 판단된다.

이번 2017년 1차 신빙도조사 중 MPI-17-01 Diphyllobothrium sp.는 $27.2 \%$ 로 매우 낮은 정답률을 보이면서 9 개로 다양한 오답을 제시하였는데, 이는 이미지 왜곡으로 인한 systemic error만으로는 설명하기 어려웠다. 이는 평소 검사 실에서 접하기 어려운 광절열두조충증의 경우 검경 경험의 부 족으로 인한 판독 오류일 가능성을 시사하였다. 지난 2015년 신빙도조사에서도 검사실에서 평소 접할 수 있는 편충란에 대 해서는 높은 정답률을 보였지만, 분선충 유충이나 왜소조충란 에 대해서는 낮은 일치도를 보여 실제 검사실에서 다양한 기생 충증에 대한 검경 경험의 부족으로 위양성 또는 위음성 결과를 보일 수 있음을 시사한 바 있다[4]. 러시아에서도 대변검경검 사에 대한 외부정도관리를 가상 슬라이드 판독을 이용하여 시 행하였을 때, 원충류나 크기가 작은 기생충 충란에 대한 판독 능력이 검사실마다 다양하고 일치율이 낮다고 보고한 바 있다 


\section{Journal of LABORATORY MEDICINE and QUALITY ASSURANCE}

Eun Jeong Won et al • EQA for Clinical Parasitology

[8]. 따라서 기생충검사의 신빙도조사는 실제 검사실에서 접 할 수 있는 다양한 기생충증에 대한 지속적인 교육이 동반되어 야 할 것으로 판단된다.

기생충 충란의 단일 이미지를 이용한 신빙도조사로는 검경 자가 실제적으로 현미경을 다루는 영역까지는 판단할 수 없 는 한계가 있기 때문에 3 차 신빙도조사에서는 표준 슬라이드 를 제조하여 배포함으로써 이를 극복하고자 하였다. 그 결과 $96.7 \%$ 의 대다수 기관에서 표준 슬라이드를 이용한 적절한 검 경능을 가지고 요충증을 진단할 수 있음을 확인하였다. 2015 년도 126 기관에 비해 1.5-1.7배 증가한 참가기관 수를 감안하 여 향후 일부 기생충 종류에 따른 수급 여부에 따라 표준 슬라 이드뿐 아니라 가상 슬라이드를 이용한 판독 역시 적용할 수 있으리라 본다[4,8].

이번 2017년 신빙도조사의 기생충검사 프로그램에서는 이 미지 검체 및 표준 슬라이드를 통한 외부정도관리를 수행하였 다. 현재는 주로 장내기생충을 진단하기 위한 대변검경검사만 을 대상으로 하고 있지만, 향후 혈액매개성 기생충 및 조직침 범 기생충 등 다양한 기생충질환의 진단을 위한 신빙도조사가 이뤄져야 할 것이다. 또한 향후 기생충 시료를 이용한 표준물 질을 확보하여 궁극적으로는 기생충질환의 진단을 위한 검사 의 일련 과정을 아우르는 신빙도조사가 이뤄져야 할 것이다.

\section{감사의 글}

기생충 양성 시료 확보를 위해 도움을 주신 한국건강관리협 회 채종일 회장님께 감사의 말씀을 전한다.

\section{REFERENCES}

1. Jones RN, Glick T, Sader HS, Flamm RK, Ross JE, Rhomberg PR, et al. Educational antimicrobial susceptibility testing as a critical component of microbiology laboratory proficiency programs: American Proficiency Institute results for 2007-2011. Diagn Microbiol Infect Dis 2013;75:357-60.
2. Snell JJ, Brown DF, Perry SF, George R. Antimicrobial susceptibility testing of enterococci: results of a survey conducted by the United Kingdom National External Quality Assessment Scheme for Microbiology. J Antimicrob Chemother 1993;32:401-11.

3. Chaitram JM, Jevitt LA, Lary S, Tenover FC; WHO Antimicrobial Resistancce Group. The World Health Organization's External Quality Assurance System Proficiency Testing Program has improved the accuracy of antimicrobial susceptibility testing and reporting among participating laboratories using NCCLS methods. J Clin Microbiol 2003;41:2372-7.

4. Chang J, Kim MN, Kim EC, Shin JH, Lee NY, Kim S, et al. Annual report on the external quality assessment scheme for clinical microbiology in Korea (2015). J Lab Med Qual Assur 2016;38:169-93.

5. Kwon YJ, Won EJ, Kee SJ, Kim SH, Shin MG, Shin JH, et al. Internal quality assurance status of stool examination as assessed by a questionnaire in Korean clinical laboratories. Lab Med Online 2018;8:19-23.

6. Won EJ, Jung JS, Lee JH, Choi HJ, Kee SJ, Kim SH, et al. Detection of intestinal parasites in diarrhea samples using various diagnostic methods and evaluation of the stability of in-house quality control materials for stool examination. J Lab Med Qual Assur 2017;39:90-6.

7. Jahan N, Khatoon R, Ahmad S. A comparison of microscopy and enzyme linked immunosorbent assay for diagnosis of Giardia lamblia in human faecal specimens. J Clin Diagn Res 2014;8:DC04-6.

8. Dovgalev AS, Astanina SY, Malakhov VN, Serdyuk AP, Imamkuliev KD, Gorbunova YP, et al. External quality assessment for the laboratory identification of the pathogens of parasitic diseases as an element for improving the postgraduate training of specialists. Med Parazitol (Mosk) 2016;(2):41-4. 
기생충검사 신빙도조사 결과보고(2017)

원은정 ${ }^{1} \cdot$ 정지승 ${ }^{1} \cdot$ 신명근 $^{2} \cdot$ 신종희 $^{2} \cdot$ 서순팔 $^{2}$

전남대학교 의과대학 ${ }^{1}$ 기생충학교실, ${ }^{2}$ 진단검사의학교실

대한임상검사정도관리협회 신빙도조사 중 기생충검사 프로그램은 2017년 3월, 5월, 8월에 시행하 였다. 1차는 4개의 이미지 검체(MPI-17-01, MPI-17-02, MPI-17-03, MPI-17-04), 2차는 3개의 이미지 검체(MPI-17-05, MPI-17-06, MPI-17-07), 마지막 3차는 기생충 시료를 이용한 슬라이 드 검체(MPS-17-01)를 참여기관에 배부하였다. 1, 2차의 이미지 검체는 교육용으로 보관 중인 양 성 시료의 포르말린-에테르 농축액을 이용하여 제작한 슬라이드를 촬영하여 제작하였다. 3차 신빙 도조사에 배포한 슬라이드는 셀로판테이프법에서 요충 충란을 확인하여 요충증을 진단한 후 보관 중이던 셀로판테이프를 이용하여 제작하였다. 2017년 기생충검사 신빙도조사 참여기관은 1차에 서 191기관, 2차에서 204기관, 3차에서 212기관이었다. 1차의 경우 MPI-17-01 Diphyllobothrium species (sp.)는 27.2\%, 기생충이 없었던 MPI-17-02는 96.6\%, MPI-17-03 Metagonimus yokogawai.는 67.5\%, MPI-17-04 Balantidium coli는 71.2\%의 정답률을 보였다. 2차의 경우 MPI17-05 Taenia sp.는 99.0\%, MPI-17-06 Trichuris trichiura는 99.0\%, MPI-17-07 Cryptosporidium $\mathrm{sp}$.는 92.7\%의 정답률을 보였다. 3차의 경우 MPS-17-01 Enterobius vermicularis는 96.7\%의 정답 률을 보였다. 이번 2017년 신빙도조사의 기생충검사 프로그램에서는 이미지 검체 및 표준 슬라이 드를 통한 외부정도관리를 수행하였다. 기생충검사의 신빙도조사는 실제 검사실에서 접할 수 있으 나 검경 경험이 적은 경우 다양한 기생충증에 대한 지속적인 교육이 동반되어야 할 것으로 판단된 다. 향후 기생충 시료를 이용한 표준물질을 확보하여 궁극적으로는 기생충질환의 진단을 위한 검사 의 일련 과정을 아우르는 신빙도조사가 이뤄져야 할 것이다.

(J Lab Med Qual Assur 2018;40:21-26)

교신저자: 원은정

우)61469 광주시 동구 백서로 160, 전남대학교 의과대학 기생충학교실

Tel: 061)379-2701, Fax: 061)375-5834, E-mail: Parasite.woni@jnu.ac.kr 